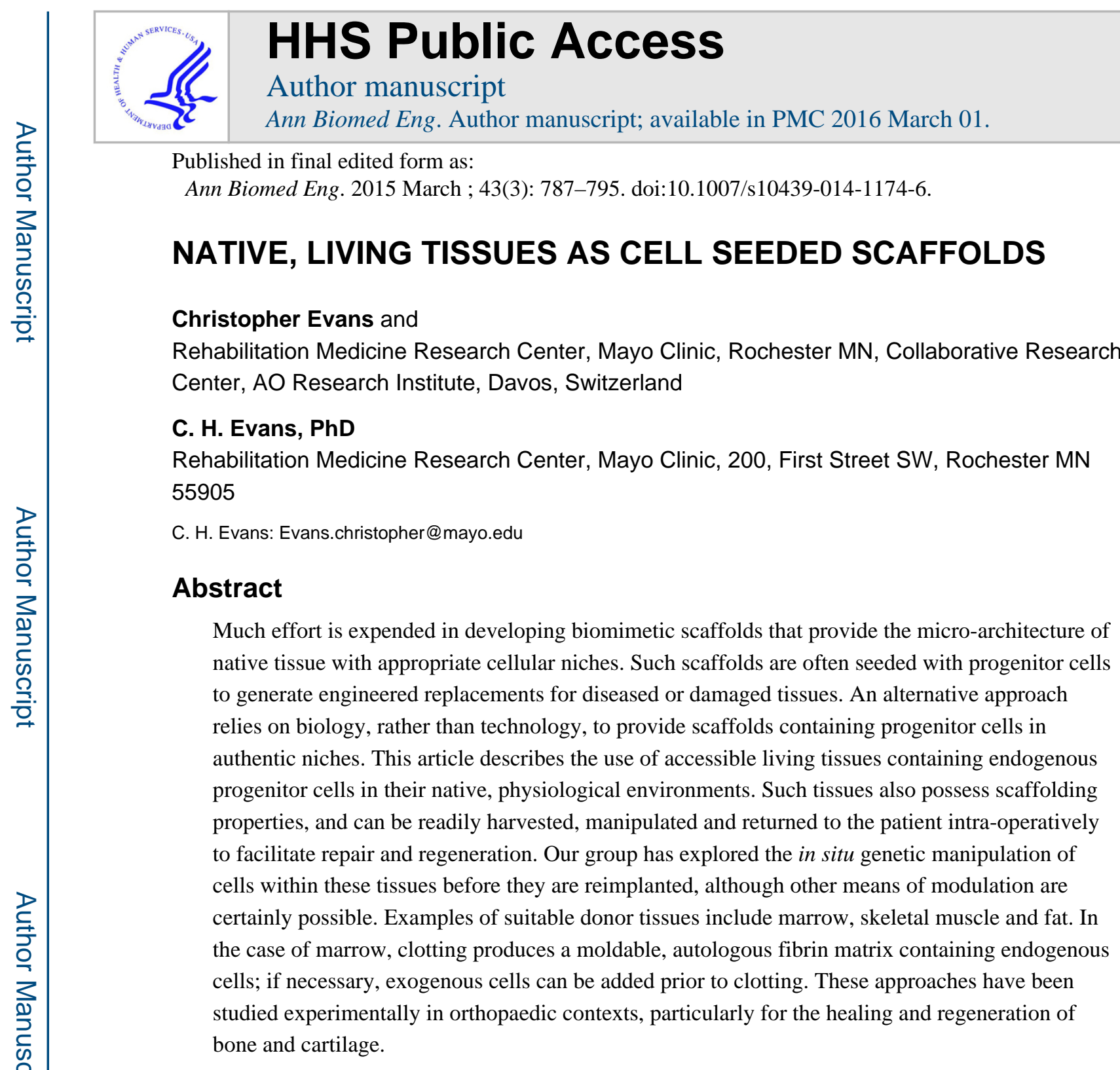

\title{
Introduction
}

Of the various strategies employed for tissue engineering and regenerative medicine, there is much interest in the use of biomimetic, cell-seeded scaffolds $(1 ; 2)$. In many cases, the cells in question are autologous progenitors that have been expanded in culture before inoculation onto scaffolds designed to provide an authentic, pericellular microenvironment. After a period of further in vitro incubation, during which differentiation of the cells may be initiated, the construct is implanted. While effective in certain circumstances, this strategy has limitations.

One issue is the need for two invasive procedures, one to harvest autologous cells and the other to implant them. This drawback can be mitigated if cells are recovered in a minimally invasive fashion, such as from peripheral blood (3) or urine (4), or if allogeneic cells are employed (5). However, many protocols use tissues that require more intrusive harvesting. A second issue is the isolation and expansion of cells under Good Manufacturing Practice (GMP) conditions, something that is tedious and expensive. Finally, when the expanded 
cells are seeded onto the scaffold, they will need authentic cell niches to restore their appropriate differentiation capacity and function. Re-creating such niches is proving difficult, especially as in many cases the niche remains poorly characterized (6).

An alternative approach relies on biology, rather than technology, to provide scaffolds containing progenitor cells in authentic niches. This strategy harvests accessible donor tissues that contain progenitor cells and have scaffolding properties. This tissue is then manipulated in an appropriate fashion to initiate the required differentiation of its progenitor cell population before transfer into the repair site. This could be performed in a single, intraoperative procedure. Because the intra-operative window of opportunity is short, our group has focused on the use of gene transfer to initiate differentiation of the tissue grafts (7-9). Adenovirus vectors hold many advantages in this setting, because they are straightforward to produce at high titer, very infectious to many different cell types, provide high levels of transgene expression and normally express in vivo for 3-6 weeks before they are cleared by endogenous biological mechanisms; this period of time may be well suited to the needs of tissue regeneration (7). Pre-clinical data from the orthopaedic arena, using marrow, muscle and fat, provide support for this concept.

\section{Bone marrow}

Bone marrow has long been recognized as a source of multipotent progenitor cells of value for regenerating bone, cartilage and a variety of other orthopaedic tissues (10). Although marrow is not a solid organ, marrow aspirates soon clot, forming an autologous fibrin scaffold containing progenitor cells. In many cases, natural wound healing is initiated by cells in fibrin clots, confirming their suitability for tissue repair and ability to provide progenitor cells with an appropriate environment for this purpose. One advantage of using marrow aspirates in this fashion is the accessibility of the cells to modulating agents before the clot forms, thereby maximizing opportunities for purposeful manipulation. Our group has taken advantage of this by transducing marrow cells with viral vectors during this window. An additional advantage of this method is the ability to form the clot to the shape and dimensions of the defect to be repaired.

Proof of principle (figure 1) was established in the context of cartilage repair. Using a rabbit model, it was possible in one surgery to harvest marrow, transduce the marrow cells with recombinant adenovirus, allow a clot to form and press-fit the construct, known as a "geneplug", into an osteochondral defect (11) (figure 2). In addition to transducing cells trapped within the marrow as it clots in vitro, adenovirus is likely to be retained within the fibrin meshwork. Under these conditions, it can transduce additional cells as they migrate into the gene plug from underlying marrow and bone. The efficiency of gene transfer is likely to be enhanced by the high transduction efficiency of adenovirus when bound to fibrin (12).

The data confirmed minimal transduction of cells outside the defect, which is an important consideration when using transgenes, such as transforming growth factor (TGF)- $\beta_{1}$, whose products are detrimental when expressed in synovium (13). Encouraging initial results were found with this protocol using bone morphogenetic protein-2 (BMP-2) cDNA as the transgene but subsequent endochondral ossification (14) ensued (Steinert, personal 
communication). However, cartilage formed by this technology with Indian hedgehog as the transgene did not undergo ossification (Steinert, personal communication).

Rather than form a gene plug, Madry and colleagues have added recombinant adenoassociated virus vectors intra-operatively into osteochondral defects in rabbits by direct application. This transduces progenitor cells as they enter the defect from underlying tissues while the exudate clots, thus forming an in situ gene plug. Promising results were reported with vectors carrying cDNA for fibroblast growth factor-2 (15) and insulin-like growth factor-1 (16).

Ivkovic and colleagues have extended the gene plug approach to chondral defects in sheep, using TGF- $\beta_{1}$ cDNA as the transgene (17). Their data show a clear improvement over controls (figure 3), and the representation of type II collagen within the repair tissue was equivalent to that of native cartilage. This is noteworthy, because restoring physiological amounts of type II collagen, unlike proteoglycan, in repair cartilage is difficult. The sheep experiments also confirmed the clinical feasibility of the technology, noting that the entire procedure could be performed by 2 surgeons in 30-45 minutes (17).

Despite these encouraging results, healing of the defects in sheep was incomplete. It is possible that the gene plug contains insufficient chondroprogenitor cells to fill a defect that is entirely chondral and thus lacks access to additional cells entering from the bone marrow. Experiments using rabbits have confirmed the possibility to augment the cellularity of the gene plug by the addition of exogenous cells, which provides a possible way to overcome this limitation. The exogenous cells may be genetically modified prior to addition (11). Gianotti et al. have recently demonstrated the feasibility of using autologous fibrin clots formed from plasma to deliver autologous, genetically unmodified, mesenchymal stromal cells for bone healing in a clinical trial (18).

\section{Skeletal Muscle}

Skeletal muscle has a remarkable propensity to form bone. This is seen at its most extensive in the genetic disease fibrodysplasia ossificans progressiva (FOP), caused by an activating mutation in a BMP receptor (19). Accelerated osteogenesis is often triggered in these patients by an injury. Formation of heterotopic bone in muscle also occurs in unaffected individuals after blast injuries (20) and certain types of surgery (21). Moreover, it has been known since the time of Urist that the introduction of osteoinductive materials into skeletal muscle provokes a marked osteogenic response (22).

Evans et al (23) undertook a series of experiments to determine whether the high osteogenicity of muscle could be harnessed for bone healing. This was evaluated in a rat segmental defect model, using in situ transduction with adenovirus carrying BMP-2 cDNA (Ad.BMP-2) to provide an osteogenic signal to the muscle grafts. Preliminary experiments confirmed that it is possible to transduce cells within muscle biopsies in situ using adenovirus vectors. Healing of critical size defects using genetically modified muscle grafts was remarkably effective in Fischer rats, which are syngeneic and therefore serve as surrogates for autografting (figure 4). Efficiency was much reduced in Sprague-Dawley rats which, although inbred, are not syngeneic. This indicates the sensitivity of this method to 
immune activation, suggesting that allografted muscle would not work. Syngeneic muscle grafts transduced with Ad.BMP-2 were also able to form bone in rat cranial defects (24).

Osteogenesis in the muscle of patients with $F O P$ and in rats receiving genetically modified muscle grafts is endochondral. Moreover, unmodified muscle grafts implanted in segmental defects in rats underwent spontaneous, delayed chondrogenesis in certain animals (23). This suggested a possible role for muscle grafts in healing cartilage defects; this was evaluated in a pilot study in rabbits. Grafts of autologous muscle were transduced with Ad.BMP-2 and implanted into osteochondral defects in trochlear grooves and femoral condyles (23). Examination of the defects 6 weeks later revealed marked improvement in restoration of both cartilage and subchondral bone in response to the genetically modified muscle (figures 5 and 6). Although the inserted muscle grafts were presumably isotropic, it is noteworthy that the regions closest to the joint space formed cartilage and the deeper regions, bone. Presumably local cues are important determinants of cell fate. Longer-term studies are required to determine whether the newly formed cartilage remains intact, degenerates or undergoes endochondral ossification.

Genetically modified muscle grafts have also been used as adjuncts to tendon repair in a rat Achilles tendon model $(25 ; 26)$.

\section{Fat}

Unlike muscle, autologous adipose tissue is readily available in large quantities. Partly for this reason it is increasingly popular as a source of progenitor cells, and large numbers of such cells can be recovered from relatively small biopsies (27). Its physical properties are such that intact adipose biopsies can serve as space filling scaffolds and it is possible to transduce cells within intact biopsies of fat (23).

Grafts of genetically modified fat are able to heal critical sized defects in rat femora (figure 4), although less reliably than equivalent grafts of muscle (23). In preliminary experiments using osteochondral defects in rabbits, genetically modified fat grafts produced a repair equivalent to that produced by muscle grafts (23) (figures 5 and 6).

Adipose tissue contains many different cells types, several of which have the potential to differentiate into osteoblasts or chondrocytes (28). Pericytes are present, but experiments to determine whether these cells contribute to the repair tissue have not been performed. The various types of cells within fat may synergize to provide a regenerative response that is superior to that of isolated, homogeneous populations of passaged cells.

\section{Tendon and ligament}

Both tendon (29) and ligament (30) contain multipotent progenitor cells that could be used for tissue engineering. Although this has not yet been exploited in the specific context of the present article, where tissue is harvested, modified and reimplanted during one operation, it has been evaluated in the related strategy of in vivo tissue engineering (31). In this technology, formation of the new tissue is initiated ectopically in vivo by manipulation of the progenitor tissue, and subsequently transplanted to the repair site. This general approach 
was first demonstrated by Stevens et al. (32) who formed bone by introducing an alginate gel between the tibia and periosteum of rabbits. After 6 weeks, the newly formed bone was transplanted into defects in the contralateral tibia, with subsequent healing. A variation of this approach has been used clinically by using the body as its own bioreactor for forming bone within the lattissimus dorsi muscle (33). The ectopically formed bone was then transplanted into a mandibular defect.

Ozeki et al. (34) were able to regenerate meniscal tissue in rat knees using transplanted Achilles tendon. BMP-7 was first injected into the tendon to initiate differentiation of multipotent progenitor cells into fibrochondrocytes. The tendon was then transplanted into the site of a large meniscal defect in the same animal, where it regenerated the lost meniscal tissue. Moreover, it prevented the degeneration of articular cartilage that would otherwise occur as a result of subsequent osteoarthritis. As autologous tendon grafts are already used clinically in meniscal reconstruction and BMP-7 is approved for human use in certain circumstances, this procedure seems well placed for clinical translation.

\section{Discussion}

Our bodies have a surprising, but latent, ability to regenerate that can be drawn upon to aid the restoration of damaged tissues (35). In particular, there are reservoirs of endogenous, multipotent progenitor cells in many tissues that are amenable to ready biopsy, modification and re-implantation. As reflected in this review, the literature on their activation in this manner is small, but the examples described here show considerable promise in pre-clinical, animal models. Most of the examples in the literature rely on the use of viral vectors for gene transfer, which raise concerns regarding safety and clinical translation (36). While the use of gene therapy certainly increases the cost, complexity and time-line for entering and completing clinical trials, a growing number of protocols in tissue engineering and regenerative medicine are entering human trials; indeed, the field of gene therapy as a whole is finally gaining traction. Non-viral vectors provide the potential to expedite the process of translation but their use is constrained by transient, low level expression of the genes they carry. As noted by the work of Ozeki et al (34), described earlier in this review, it may prove possible to achieve the in situ differentiation of progenitor cells using a single application of a recombinant protein, rather than a vector, which would simplify the process even further. It may also be possible using small molecules (37). All examples of using modified native tissues so far are drawn from the orthopaedic arena, and it is unclear whether this technology can be extended to the regeneration of complex organs.

As noted, the abbreviated ex vivo strategies favored by our group compliment the in vivo tissue engineering protocols (31) of other investigators. These, in turn, merge into the in situ tissue engineering ideas initiated by Goldstein and Bonadio (38) where tissue regeneration occurs within the lesion without the need for secondary manipulations.

\section{Acknowledgments}

The author's work in this area has been supported by the AO Foundation and by NIH grants R01 AR050243 and R01 AR052809 from NIAMS. 
I thank Dr. Andre Steinert for permission to mention his unpublished data, Dr. Alan Ivkovic for permission to use figure 3 and Prof. Steven Ghivizzani for supplying figure 2. Dr. Declan Devine is thanked for advice and discussion.

\section{References}

1. Lim EH, Sardinha JP, Myers S. Nanotechnology biomimetic cartilage regenerative scaffolds. Archives of plastic surgery. 2014; 41:231-40. [PubMed: 24883273]

2. Holzwarth JM, Ma PX. Biomimetic nanofibrous scaffolds for bone tissue engineering. Biomaterials. 2011; 32:9622-9. [PubMed: 21944829]

3. Zhang Y, Huang B. Peripheral blood stem cells: phenotypic diversity and potential clinical applications. Stem cell reviews. 2012; 8:917-25. [PubMed: 22451417]

4. Benda C, Zhou T, Wang X, Tian W, Grillari J, et al. Urine as a source of stem cells. Advances in biochemical engineering/biotechnology. 2013; 129:19-32. [PubMed: 23038280]

5. Wheeler DL, Lane JM, Seim HB 3rd, Puttlitz CM, Itescu S, Turner AS. Allogeneic mesenchymal progenitor cells for posterolateral lumbar spine fusion in sheep. The spine journal : official journal of the North American Spine Society. 2014; 14:435-44. [PubMed: 24438940]

6. Meng X, Leslie P, Zhang Y, Dong J. Stem cells in a three-dimensional scaffold environment. SpringerPlus. 2014; 3:80. [PubMed: 24570851]

7. Evans CH, Robbins PD. Genetically augmented tissue engineering of the musculoskeletal system. Clinical orthopaedics and related research. 1999:S410-8. [PubMed: 10546663]

8. Evans CH, Palmer GD, Pascher A, Porter R, Kwong FN, et al. Facilitated endogenous repair: making tissue engineering simple, practical, and economical. Tissue engineering. 2007; 13:198793. [PubMed: 17518747]

9. Evans C. Using genes to facilitate the endogenous repair and regeneration of orthopaedic tissues. International orthopaedics. 2014; 38:1761-69. [PubMed: 25038968]

10. Charbord P. Bone marrow mesenchymal stem cells: historical overview and concepts. Human gene therapy. 2010; 21:1045-56. [PubMed: 20565251]

11. Pascher A, Palmer GD, Steinert A, Oligino T, Gouze E, et al. Gene delivery to cartilage defects using coagulated bone marrow aspirate. Gene therapy. 2004; 11:133-41. [PubMed: 14712297]

12. Neumann AJ, Schroeder J, Alini M, Archer CW, Stoddart MJ. Enhanced adenovirus transduction of hMSCs using 3D hydrogel cell carriers. Molecular biotechnology. 2013; 53:207-16. [PubMed: 22382454]

13. Mi Z, Ghivizzani SC, Lechman E, Glorioso JC, Evans CH, Robbins PD. Adverse effects of adenovirus-mediated gene transfer of human transforming growth factor beta 1 into rabbit knees. Arthritis research \& therapy. 2003; 5:R132-9. [PubMed: 12723985]

14. Steinert AF, Proffen B, Kunz M, Hendrich C, Ghivizzani SC, et al. Hypertrophy is induced during the in vitro chondrogenic differentiation of human mesenchymal stem cells by bone morphogenetic protein- 2 and bone morphogenetic protein- 4 gene transfer. Arthritis research \& therapy. 2009; 11:R148. [PubMed: 19799789]

15. Cucchiarini M, Madry H, Ma C, Thurn T, Zurakowski D, et al. Improved tissue repair in articular cartilage defects in vivo by rAAV-mediated overexpression of human fibroblast growth factor 2 . Molecular therapy : the journal of the American Society of Gene Therapy. 2005; 12:229-38. [PubMed: 16043094]

16. Cucchiarini M, Madry H. Overexpression of human IGF-I via direct rAAV-mediated gene transfer improves the early repair of articular cartilage defects in vivo. Gene therapy. 2014; 21:811-9. [PubMed: 24989812]

17. Ivkovic A, Pascher A, Hudetz D, Maticic D, Jelic M, et al. Articular cartilage repair by genetically modified bone marrow aspirate in sheep. Gene therapy. 2010; 17:779-89. [PubMed: 20220780]

18. Giannotti S, Trombi L, Bottai V, Ghilardi M, D'Alessandro D, et al. Use of autologous human mesenchymal stromal cell/fibrin clot constructs in upper limb non-unions: long-term assessment. PloS one. 2013; 8:e73893. [PubMed: 24023694] 
19. Shore EM, Xu M, Feldman GJ, Fenstermacher DA, Cho TJ, et al. A recurrent mutation in the BMP type I receptor ACVR1 causes inherited and sporadic fibrodysplasia ossificans progressiva. Nature genetics. 2006; 38:525-7. [PubMed: 16642017]

20. Forsberg JA, Pepek JM, Wagner S, Wilson K, Flint J, et al. Heterotopic ossification in high-energy wartime extremity injuries: prevalence and risk factors. The Journal of bone and joint surgery. 2009; 91:1084-91. American volume. [PubMed: 19411456]

21. Zeckey C, Hildebrand F, Frink M, Krettek C. Heterotopic ossifications following implant surgery-epidemiology, therapeutical approaches and current concepts. Seminars in immunopathology. 2011; 33:273-86. [PubMed: 21240489]

22. Van de Putte KA, Urist MR. Osteogenesis in the interior of intramuscular implants of decalcified bone matrix. Clinical orthopaedics and related research. 1965; 43:257-70. [PubMed: 5323974]

23. Evans CH, Liu FJ, Glatt V, Hoyland JA, Kirker-Head C, et al. Use of genetically modified muscle and fat grafts to repair defects in bone and cartilage. European cells \& materials. 2009; 18:96-111. [PubMed: 20073015]

24. Liu F, Porter RM, Wells J, Glatt V, Pilapil C, Evans CH. Evaluation of BMP-2 gene-activated muscle grafts for cranial defect repair. Journal of orthopaedic research : official publication of the Orthopaedic Research Society. 2012; 30:1095-102. [PubMed: 22213093]

25. Majewski M, Porter RM, Betz OB, Betz VM, Clahsen H, et al. Improvement of tendon repair using muscle grafts transduced with TGF-beta1 cDNA. European cells \& materials. 2012; 23:94-101. discussion-2. [PubMed: 22354460]

26. Majewski M, Betz O, Ochsner PE, Liu F, Porter RM, Evans CH. Ex vivo adenoviral transfer of bone morphogenetic protein 12 (BMP-12) cDNA improves Achilles tendon healing in a rat model. Gene therapy. 2008; 15:1139-46. [PubMed: 18432278]

27. Ong WK, Sugii S. Adipose-derived stem cells: fatty potentials for therapy. The international journal of biochemistry \& cell biology. 2013; 45:1083-6. [PubMed: 23458962]

28. Lin CS, Lue TF. Defining vascular stem cells. Stem cells and development. 2013; 22:1018-26. [PubMed: 23330734]

29. Bi Y, Ehirchiou D, Kilts TM, Inkson CA, Embree MC, et al. Identification of tendon stem/ progenitor cells and the role of the extracellular matrix in their niche. Nature medicine. 2007; 13:1219-27.

30. Steinert AF, Kunz M, Prager P, Barthel T, Jakob F, et al. Mesenchymal stem cell characteristics of human anterior cruciate ligament outgrowth cells. Tissue engineering Part A. 2011; 17:1375-88. [PubMed: 21247268]

31. McCullen SD, Chow AG, Stevens MM. In vivo tissue engineering of musculoskeletal tissues. Current opinion in biotechnology. 2011; 22:715-20. [PubMed: 21646011]

32. Stevens MM, Marini RP, Schaefer D, Aronson J, Langer R, Shastri VP. In vivo engineering of organs: the bone bioreactor. Proceedings of the National Academy of Sciences of the United States of America. 2005; 102:11450-5. [PubMed: 16055556]

33. Warnke PH, Springer IN, Wiltfang J, Acil Y, Eufinger H, et al. Growth and transplantation of a custom vascularised bone graft in a man. Lancet. 2004; 364:766-70. [PubMed: 15337402]

34. Ozeki N, Muneta T, Koga H, Katagiri H, Otabe K, et al. Transplantation of Achilles tendon treated with bone morphogenetic protein 7 promotes meniscus regeneration in a rat model of massive meniscal defect. Arthritis and rheumatism. 2013; 65:2876-86. [PubMed: 23897174]

35. Evans CH. Advances in regenerative orthopedics. Mayo Clinic proceedings. 2013; 88:1323-39. [PubMed: 24182709]

36. Evans CH, Ghivizzani SC, Robbins PD. Orthopedic gene therapy--lost in translation? Journal of cellular physiology. 2012; 227:416-20. [PubMed: 21948071]

37. Johnson K, Zhu S, Tremblay MS, Payette JN, Wang J, et al. A stem cell-based approach to cartilage repair. Science. 2012; 336:717-21. [PubMed: 22491093]

38. Bonadio J, Smiley E, Patil P, Goldstein S. Localized, direct plasmid gene delivery in vivo: prolonged therapy results in reproducible tissue regeneration. Nature medicine. 1999; 5:753-9. 


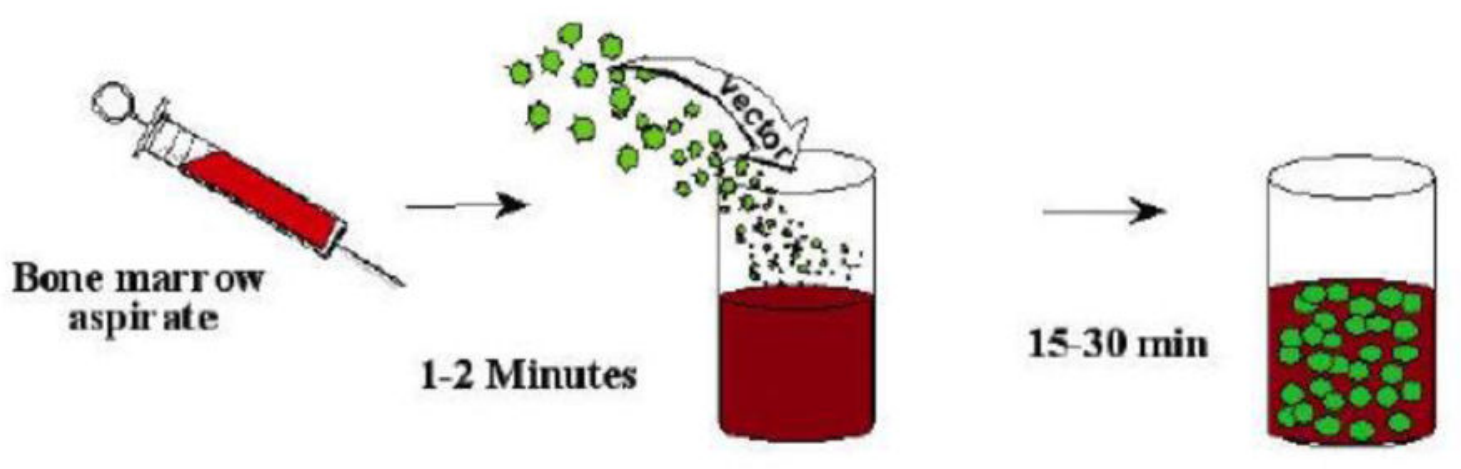

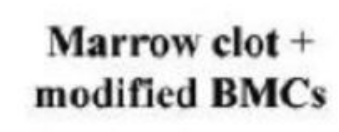

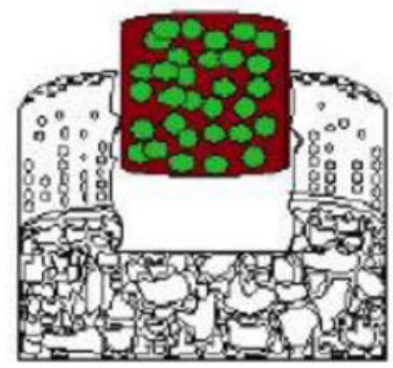

\section{Localized transgene \\ expression and containment of free vector}

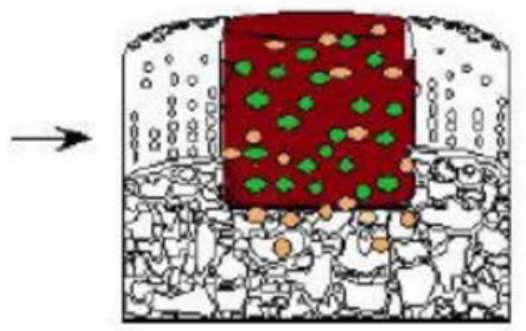

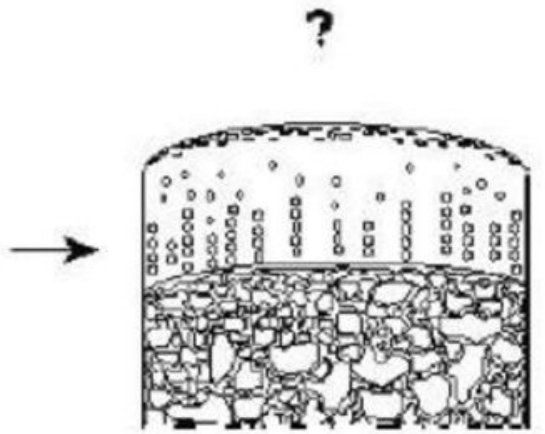

Figure 1. Concept of gene transfer to osteochondral defects using genetically modified, clotted, autologous bone marrow

Freshly aspirated marrow is mixed with a vector that carries appropriate reparative cDNAs, and is allowed to clot in a suitably shaped container. The clot, which now contains genetically modified marrow cells and bound vector, is press-fit into the defect. Expression of the transgenes promotes differentiation of progenitor cells within the lesion along the appropriate lineages to regenerate cartilage and subchondral bone.

From reference 8, with permission. 


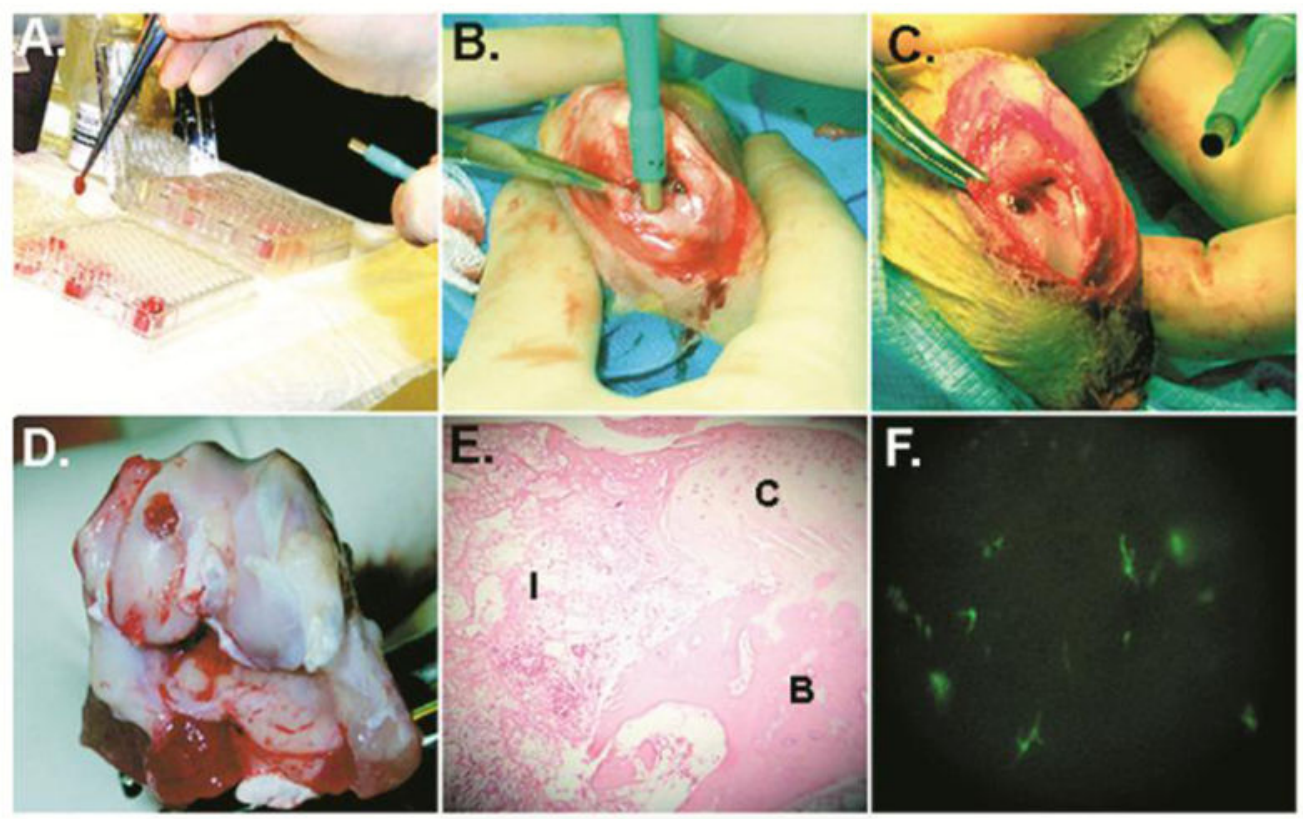

Figure 2. Gene delivery to osteochondral defects using bone marrow clots (a-c) Fresh aspirates of bone marrow were mixed with $10^{10} \mathrm{vp}$ of Ad.Luc or Ad.GFP, and allowed to coagulate in individual wells of a 96-well plate. The clots were removed with forceps, loaded into a $3 \mathrm{~mm}$ diameter tube fitted with a plunger, and implanted into $3 \times 8$ $\mathrm{mm}$ osteochondral defects generated in the femoral condyles of rabbits. At periodic intervals postimplantation, the knees were harvested and implants examined. ( $d$ and e) Example of a clot implant at day 7; the clots were maintained within the lesion, and had integrated into surrounding tissues. (f) Fluorescent microscopy of the synovial lining of joints receiving clots seeded with Ad.GFP. There is little transduction of synovial cells.

From reference 11, with permission. 

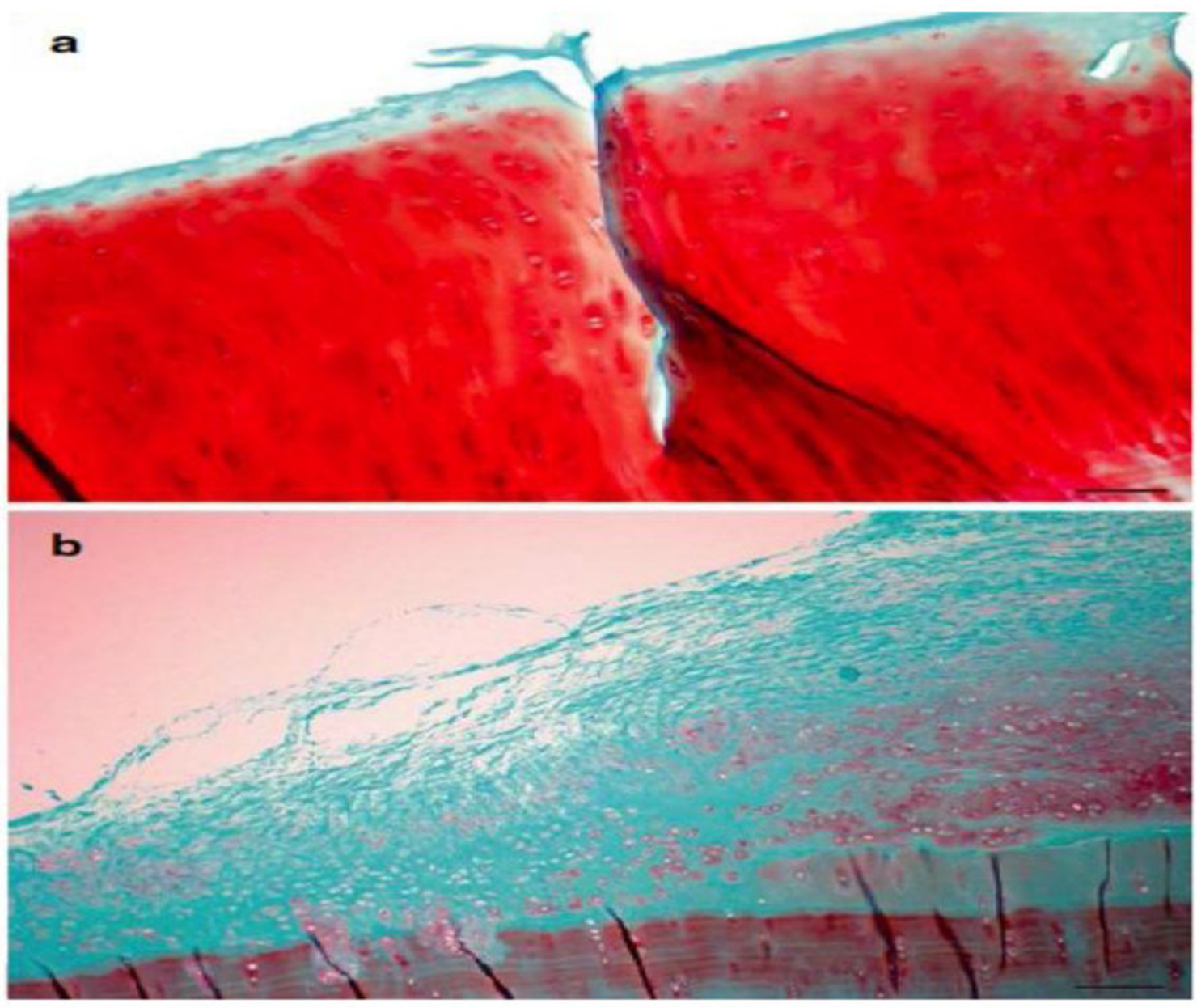

Figure 3. Histological appearance of repair cartilage in sheep formed after treatment with a TGF $-\beta_{1}$ gene plug compared to control

Cartilage defects in sheep were treated either with bone marrow clot genetically modified to secrete TGF- $\beta_{1}$ (a) or left untreated (b). After 6 months histology revealed formation of hyaline cartilage (stained red) in genetically treated defects and mixture of fibrous tissue (stained green) and fibrocartilage in untreated defects. Staining: Safranin O; scale bar $=100$ $\mu \mathrm{m}$

From reference 17, with permission. 


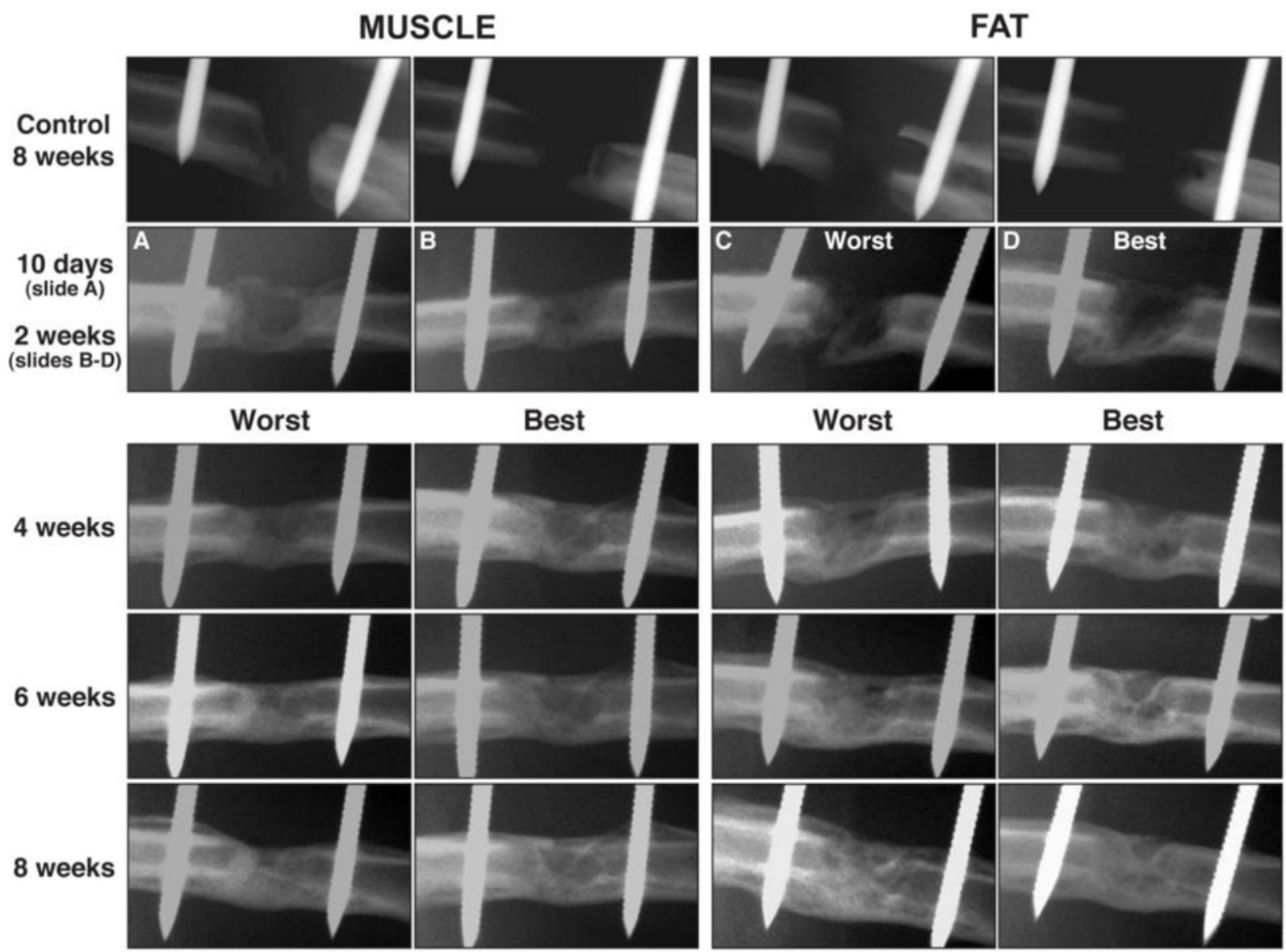

Figure 4. Serial radiographs of defects in rat femora following the implantation of gene-activated muscle and fat grafts

Control defects received tissue grafts transduced with control virus carrying marker genes. Radiologic bridging can be seen in as little as 10 days when using Ad.BMP-2 modified muscle grafts. Healing is slower using Ad.BMP-2 modified fat, with radiolucency at 10 days, and bridging seen only by 2 weeks. Images from 2 weeks onward (fat) and 4 weeks onwards (muscle) show the best and worst healers, based on radiologic appearance, in each group of rats.

From reference 23. 


\section{Empty Condylar Defect}

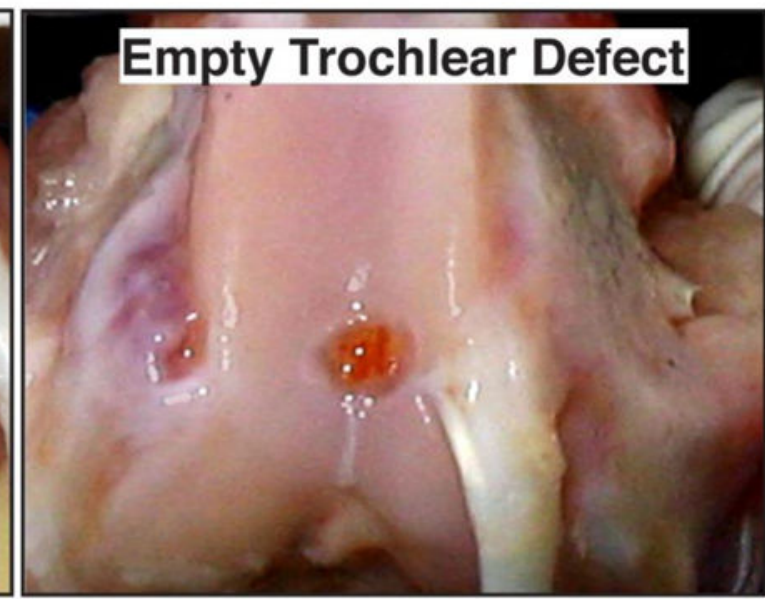

\section{Activated Fat Graft}

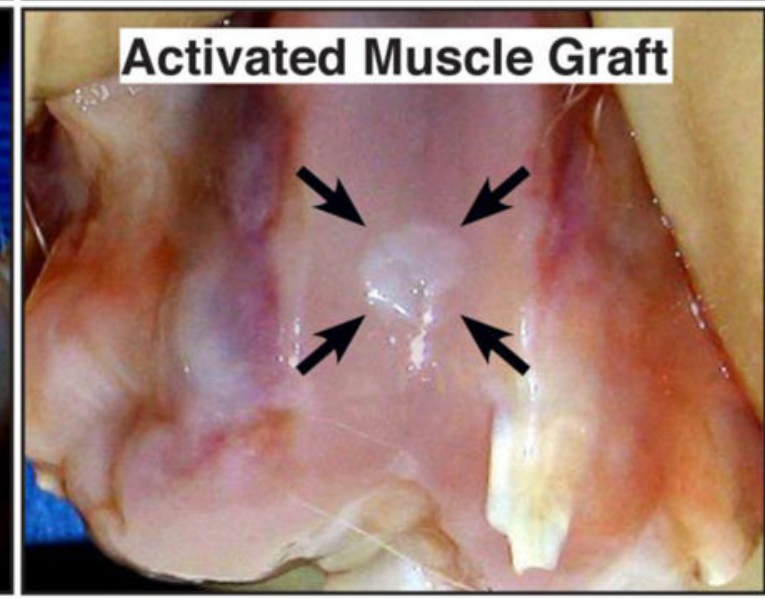

Figure 5. Macroscopic images of control osteochondral defects and defects treated with geneactivated muscle and fat

Rabbits were euthanized 6 weeks after surgery. Arrows indicate site of original defect and implantation of tissue. Bar $=5 \mathrm{~mm}$.

From reference 23. 


\section{CONDYLE}
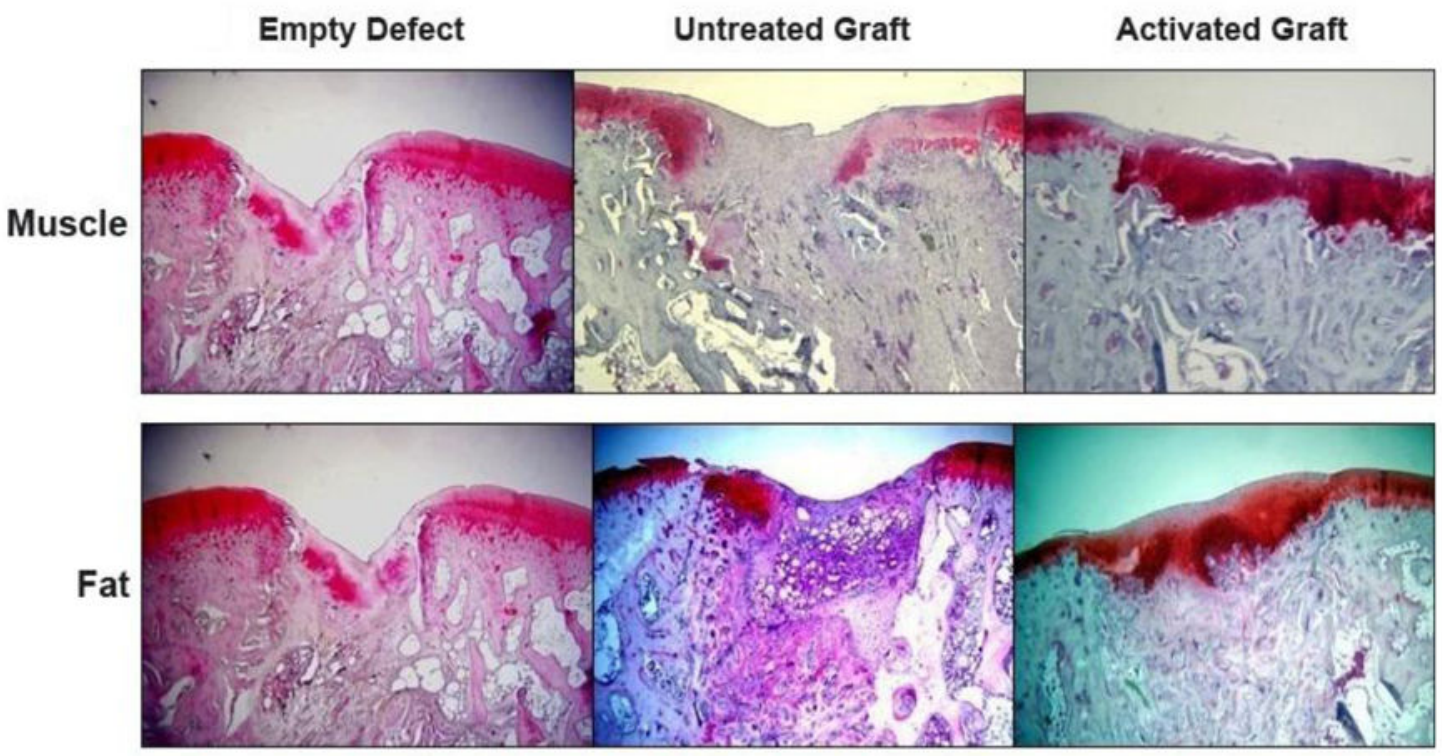

TROCHLEAR GROOVE
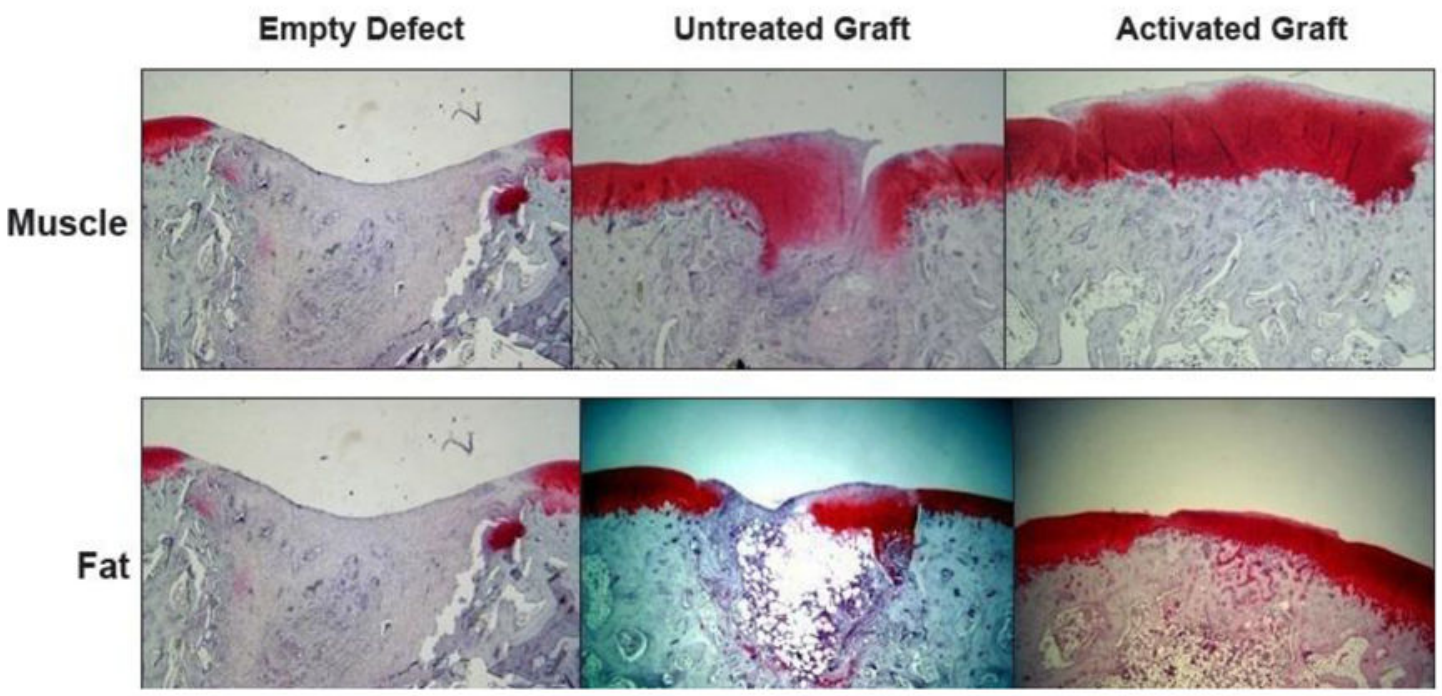

Figure 6. Histological examination of osteochondral defects receiving gene-activated muscle and fat grafts

Sections were stained with safranin O-fast green. Bar $=1 \mathrm{~mm}$

From reference 23 